\title{
Cat-scratch disease in veterinary-associated populations and in its cat reservoir in Taiwan
}

\author{
Chao-chin CHANG ${ }^{\mathrm{a}}$, Chiu-Ching LEE ${ }^{\mathrm{b}}$, Soichi MARUYAMA ${ }^{\mathrm{c}}$, \\ Jen-Wei LIN ${ }^{\mathrm{d}}$, Ming-Jeng PAN ${ }^{\mathrm{b}, \mathrm{e} *}$ \\ a Graduate Institute of Veterinary Public Health, School of Veterinary Medicine, National Chung Hsing \\ University, Taichung 402, Taiwan \\ b Department of Veterinary Medicine, National Taiwan University, Taipei 106, Taiwan \\ ${ }^{c}$ Laboratory of Veterinary Public Health, Department of Veterinary Medicine, College of Bioresource \\ Sciences, Nihon University, Kanagawa, Japan \\ ${ }^{\mathrm{d}}$ Department of Veterinary Medicine, School of Veterinary Medicine, National Chung Hsing University, \\ Taichung 402, Taiwan \\ ${ }^{\mathrm{e}}$ Institute of Medical Biotechnology, Central Taiwan University of Science and Technology, No.11, \\ Buzih Lane, Beitun District, Taichung 40601, Taiwan
}

(Received 17 August 2005; accepted 17 January 2006)

\begin{abstract}
In Taiwan, the first human case of cat-scratch disease (CSD) was diagnosed by a serologic test in 1998. Since then, no studies have been conducted to understand the epidemiology of the infection in Taiwan. Therefore, this study is the first epidemiologic survey of CSD in cats and humans in this country. Using veterinary-associated individuals as the study population, it was identified that $1.7 \%$ of them were seropositive for $B$. henselae, and residence was the only factor associated with seropositivity. Bartonella species were successfully isolated from $25(19.1 \%)$ of the 131 cats tested. Only $B$. henselae and $B$. clarridgeiae were obtained from bacteremic cats. Furthermore, $9.2 \%$ of 131 cats were dually-infected with genotypes I and II of $B$. henselae. It is the highest prevalence of co-infection that has ever been reported worldwide. In cats, the seroprevalence was $23.7 \%$ by indirect immunofluorescence antibody assay with $B$. henselae Houston-1 (type I) as the antigen. When 12 bacteremic but seronegative cats were re-tested by IFA slides coated with $B$. henselae U-4 antigen (type II), 9 cats were identified to be seropositive. Our study further suggested that using only direct PCR of 16S-23S rRNA intergenic region or the combination of the PCR method and indirect immuno-fluorescence test will be useful to diagnose Bartonella-free cats.
\end{abstract}

Bartonella / cat scratch disease / cat / veterinary-associated population / Taiwan

\section{INTRODUCTION}

Cat-Scratch Disease (CSD) is a zoonosis as domestic cats are the natural reservoir of this disease [18]. Bartonella henselae is the major causative agent of $\operatorname{CSD}[1,9,10,33]$. Though B. clarridgeiae has not been iso- lated from CSD suspected patients up to date, the species is considered to be another possible agent of CSD, based on serological findings $[19,23]$. The first CSD case in Taiwan was reported in 1998 [22]. Nevertheless, the official reference laboratory for CSD diagnosis was not established until

\footnotetext{
* Corresponding author: mjpan@ @ctust.edu.tw
} 
2001 in this country. Until now, no epidemiologic survey was conducted to understand the risks associated with CSD in cats and humans in Taiwan.

$B$. henselae transmission among cats is through the exposure of cat flea, Ctenocephalides felis [7, 18]. Humans are infected when cat-scratch or bite-wounds are contaminated with feces excreted by infected cat fleas $[12,14]$. Given this fact, veterinary professionals seem to be a high-risk population and need to be investigated. Surprisingly, there have not been many epidemiologic studies worldwide on CSD in veterinaryassociated populations. The first epidemiologic survey was conducted in veterinarians from the USA [30]. In that study, 6.0\% (18/ 198 ) of responding veterinarians selfreported a previous diagnosis of CSD, and 3 out of these 18 individual were seropositive for Bartonella. Furthermore, year of experience with cats was the only identified variable associated with seropositivity [30]. There were also two serological investigations in veterinary populations in Japan [17, 20]. Kumasaka et al. [20] reported that $15 \%$ $(35 / 233)$ of veterinary professionals were seropositive for $B$. henselae, and young female veterinary assistants and animal beauticians were more likely to be infected. Kikuchi et al. [17] reported that 10.9\% (14/ $129)$ and $0.8 \%(1 / 129)$ of healthy veterinary students were IgG- and IgM-positive for $B$. henselae, respectively. History of catexposure was the main risk factor in this study population [17].

Bartonella infection in cats has been reported from many countries in the world [5]. In Asian countries, the results showed that seroprevalence of $B$. henselae among cat populations in Japan ranged from 9.1 to $15.1 \%[28,36], 68 \%$ in Philippines [8], $48 \%$ in Singapore [29] and 54\% in Indonesia [24]. Both B. henselae and B. clarridgeiae have been isolated from cats in some of these countries, including Indonesia, Thailand, Philippines and Japan [8, 24, 26, 27]. The prevalence of bacteremia ranged from $6.4 \%$ to $89 \%$ for $B$. henselae $[8,25-27]$ and
$0.7 \%$ to $31 \%$ for $B$. clarridgeiae $[8,26,27]$. Co-infection with $B$. henselae and $B$. clarridgeiae were reported in cats from the Philippines and Japan $[8,26]$. Taiwan is located in the subtropical area, with an average temperature of $22.02{ }^{\circ} \mathrm{C}$ and relative humidity of $77.8 \%$, according to the monitoring record of the Central Weather Bureau, Taiwan in 2004. Such an environment is very suitable for growth of fleas, and fleainfested animals, such as stray cats and dogs, are commonly seen all year round. However, there has been no epidemiologic investigation on Bartonella infection in cats in Taiwan until now.

In order to elucidate the epidemiologic distribution of CSD in cats and humans in Taiwan, one major objective of this study was to determine the prevalence and risk factors of CSD in veterinary-associated populations. The other objective of the study was to perform a survey in various cat populations to understand which Bartonella species is the most prevalent and factors associated with the infection in cats in Taiwan.

\section{MATERIALS AND METHODS}

\subsection{Collection of specimens from humans}

A total of 295 human samples were collected from veterinary-associated populations in Taiwan, including 195 whole blood samples and 100 serum samples. The whole blood samples were from 114 volunteers attending a Veterinary Conference in 2002 in Taiwan, and 81 people working at the Veterinary Teaching Hospital of the National Chung Hsing University between September and October, 2002. One hundred serum samples that were originally collected to be tested for leptospiral infection in veterinary professionals, including 29 clinicians, 55 veterinary students and 16 veterinary technicians at National Taiwan University in March, 2002, were also tested for Bartonella infection. All subjects were administered a 
structured questionnaire to gather demographic, occupational and associated exposure information.

\subsection{Collection of specimens from cats}

A total of 131 cat samples were collected between March 2001 and May 2003. The cats were from 3 different cat populations in Taiwan, including 30 pet cats, 37 cats from a breeding cat farm in Tainan county and 64 impound cats from a municipal stray animal shelter in Taipei. The breeding cat farm was selected for comparison because its raising environment was under strict ectoparasite control. One to two milliliters of whole blood from each cat were collected in plastic EDTA tubes (Greiner Bio-One VACUETTE ${ }^{\circledR}$ North America, USA) from jugular or saphenous vein. Whole blood samples were centrifuged at $1000 \times g$ to separate the plasma and blood cells. Sera were prepared from plasma after full speed centrifugation. All samples were frozen at $-70{ }^{\circ} \mathrm{C}$ before tested. For the pet cats and cats from the breeding farm, descriptive data such as age, sex, neutering history, flea infestation condition of the cats were recorded by investigators through interviewing. In impounded cats, the descriptive data, including estimated age, sex, and flea infestation were recorded by the same investigator at the time of blood sampling.

\subsection{Detection of Bartonella genomic DNA from human and cat blood}

The QIAamp ${ }^{\circledR}$ DNA Blood mini Kit (QIAGEN Inc., Valencia, CA, USA) was used for extraction of DNA from $200 \mu \mathrm{L}$ of human and cat blood samples. Forty-four cats and 107 human blood specimens were tested by a single step PCR assay aiming at the $16 \mathrm{~S}-23 \mathrm{~S}$ rRNA intergenic region, as previously described [16]. Forty-four cats were selected from 131 cats by simple random sampling using a table of random number digits, for blind evaluation of sensitivity, specificity, positive predictive value and negative predictive value of the
PCR test. A total of 107 human whole blood samples were analyzed because of having enough amount of blood for DNA extraction and PCR analysis. Only whole blood samples were used for DNA extraction. Therefore, serum collected from people for the investigation of leptospirosis were not used for PCR assay. The primer set used in amplification of 16S-23S rRNA intergenic region by a single step PCR assay was BSSPF (5' -CTC TTT CTT CAG ATG ATG ATC C-3') and BSSPR (5'-AAC CAA CTG AGC TAC AAG CCC T-3'). DNA amplification was performed with PCRExpress thermo cycler (HYBAID, Ashford, UK) by the following PCR protocol: $10 \mathrm{~min}$ of incubation at $20^{\circ} \mathrm{C}$, followed by $2 \mathrm{~min}$ of denaturation at $95^{\circ} \mathrm{C}$ and then 45 cycles of $1 \mathrm{~min}$ of denaturation at $95^{\circ} \mathrm{C}, 1 \mathrm{~min}$ of annealing at $60^{\circ} \mathrm{C}$, and $30 \mathrm{~s}$ of extension at $72^{\circ} \mathrm{C}$. PCR amplification products were identified by ethidium bromide fluorescence after electrophoresis in 3\% agarose gels. As described previously by Jensen et al. [15], the amplified fragment was 202 bp for B. bacilliformis, $145 \mathrm{bp}$ for B. clarridgeiae, $232 \mathrm{bp}$ for B. elizabethae, $163 \mathrm{bp}$ for B.henselae, $148 \mathrm{bp}$ for B. quintana, $251 \mathrm{bp}$ for B. vinsonii subsp. berkhoffii.

\subsection{Isolation of Bartonella spp. in cats}

After thawing, $100 \mu \mathrm{L}$ of the blood was inoculated onto two chocolate agar plates (Creative Microbiologicals LTD., Taipei, Taiwan) and incubated at $35^{\circ} \mathrm{C}, 5 \% \mathrm{CO}_{2}$ for up to four weeks. The agar plates were regularly checked every 3 to 4 days. Identification of Bartonella-suspected colonies was based on morphological characteristics and growth time on agar plates. The number of colonies formed on the agar plates was then recorded, and colony-forming units (CFU) per milliliter of blood were calculated to represent the level of bacteremia. When the visible colonies were identified, they were subcultured and confirmed as Bartonella at the species level by molecular methods as mentioned above. The original 
isolates and their subcultures were frozen at $-70{ }^{\circ} \mathrm{C}$ for future usage.

\subsection{Molecular identification of Bartonella species and 16S rRNA genotyping}

Three to five colonies suspected to be Bartonella spp. were harvested for identification of Bartonella species by PCR of the citrate synthase gene (gltA gene) with one set of specific primers, namely BhCS.781 (5'-GGG GAC CAG CTC ATG GTG G-3') and BhCS.1137n (5'-AAT CGA AAA AGA ACA GTA AAC A-3'). The PCR products were further processed by restriction fragment length polymorphism (RFLP) analysis with Taq I (Biolabs ${ }^{\circledR}$ Inc., USA) and Hha I (Takara Biochemicals, Ohotsu, Japan) digestion [31]. Genomic DNA was obtained by boiling bacterial colonies at $100{ }^{\circ} \mathrm{C}$ for $10 \mathrm{~min}$. The template DNA was mixed with the reaction solution (10 mM Tris- $\mathrm{HCl}$, pH 9.0, $50 \mathrm{mM} \mathrm{KCl}$, $3 \mathrm{mM} \mathrm{MgCl} 2,0.01 \%$ (w/v) gelatin, $0.1 \%$ Triton X-100) containing $1 \mathrm{mM}$ of dNTPs, 20 pmol each of sense/antisense primers, $1.25 \mathrm{mg}$ bovine serum albumin (BSA, SIGMA, St. Louis, MO, USA), and 2.5 U of Taq polymerase (GeneTeks BioScience Inc., Germany), and adjusted to a final volume of $50 \mu \mathrm{L}$. DNA amplification was performed with PCRExpress thermo cycler (HYBAID) with initial denaturation $\left(95^{\circ} \mathrm{C}\right.$, 5 min), followed 35 cycles of denaturation $\left(95^{\circ} \mathrm{C}, 1 \mathrm{~min}\right)$, annealing $\left(55^{\circ} \mathrm{C}, 30 \mathrm{~s}\right)$ and extension $\left(72^{\circ} \mathrm{C}, 2 \mathrm{~min}\right)$, with a single final extension step $\left(72^{\circ} \mathrm{C}, 5 \mathrm{~min}\right)$. The amplified fragment (379 bp) was subjected to electrophoresis in a $3 \%$ agarose $\left(\mathrm{NuSieve}^{\circledR} 3: 1\right.$ agarose, BioWhittaker Molecular Applications, Rockland, ME, USA) gel and stained with $0.6 \mu \mathrm{g} / \mathrm{mL}$ ethidium bromide solution. After confirmation by electrophoresis, the amplicon was digested with TaqI and HhaI restriction endonucleases. The isolates were identified as B. henselae or B. clarridgeiae by comparing the standard band patterns of the type strains, $B$. henselae Houston-1 (American Type Culture Collec- tion, ATCC 49882) and B. clarridgeiae (ATCC 51734).

Genotyping of $B$. henselae was performed by PCR of the 16S rRNA gene as previously described by Bergmans et al. [2] with minor modifications. The reaction solution of PCR was prepared with two sets of $B$. henselae $16 \mathrm{~S}$ rRNA gene type-specific primers: $16 \mathrm{SF}$ and either $\mathrm{BH} 1$ or $\mathrm{BH} 2$. DNA amplification was performed with PCRExpress thermo cycler with initial denaturation $\left(95^{\circ} \mathrm{C}, 3 \mathrm{~min}\right)$, followed 30 cycles of denaturation $\left(95^{\circ} \mathrm{C}, 20 \mathrm{~s}\right)$, annealing $\left(56{ }^{\circ} \mathrm{C}, 30 \mathrm{~s}\right)$ and extension $\left(73{ }^{\circ} \mathrm{C}, 1 \mathrm{~min}\right)$, with a single final extension step $\left(73{ }^{\circ} \mathrm{C}, 5 \mathrm{~min}\right)$. Amplified products were subjected to electrophoresis in a $3 \%$ agarose gel and the gel was stained with $0.6 \mu \mathrm{g} / \mathrm{mL}$ ethidium bromide solution. When the specific band of $185 \mathrm{bp}$ was observed with primers $16 \mathrm{SF}$ and $\mathrm{BH} 1$, the strain was identified as type I. While the specific band of $185 \mathrm{bp}$ was observed with primers $16 \mathrm{SF}$ and $\mathrm{BH} 2$, the strain was identified as type II. The strains Houston-1 and U-4 were used as the reference strains of $B$. henselae types I and II, respectively. Strain U-4 was kindly shared by Dr Bruno B. Chomel (University of California, Davis, USA).

\subsection{B. henselae indirect immunofluorescence antibody test}

The antibody titers to $B$. henselae were determined by indirect immunofluorescence antibody test (IFA), using slides respectively made by $B$. henselae Houston-1 (ATCC 49882) and B. henselae U4 (University of California, Davis) as antigens [32]. The type strain was cultured on chocolate agar plate at $37{ }^{\circ} \mathrm{C}$ in $5 \% \mathrm{CO}_{2}$ for 4 days to grow up a confluent plate of bacteria. The cultured organisms harvested from agar plates were suspended in $0.5 \mathrm{~mL}$ phosphate buffer saline (PBS, pH 7.4) and added into $15 \mathrm{~mL}$ M199 tissue culture media (SIGMA) with 5\% fetal bovine serum (FBS, HyClone ${ }^{\circledR}$ Laboratories Inc., Logan, UT, USA). The bacteriological suspension was inoculated to a $90 \%$ confluent Vero cell 
(CCRC 60013, Bioresources Collection and Research Center, Taiwan) tissue culture flask $\left(75 \mathrm{~cm}^{2}\right)$ and incubated at $37{ }^{\circ} \mathrm{C}$ with $5 \% \mathrm{CO}_{2}$ for 2 days. After incubation, the tissue culture was washed twice with sterile calcium- and magnesium-free PBS, and then was treated with trypsin for harvesting the infected cells. After using sterile PBS to re-suspended cells, the suspension was centrifuged at $200 \times g$ for $10 \mathrm{~min}$. Then, the supernatant was discarded and the cells were resuspended in $30 \mathrm{~mL}$ growth medium for tissue culture. A volume of $30 \mu \mathrm{L}$ of suspension containing infected cell was distributed onto each well of 12-hole Teflon printed slides (Electron Microscopy Science, Hatfield, PA, USA), and the slides were incubated at $37^{\circ} \mathrm{C}$ with $5 \% \mathrm{CO}_{2}$ overnight. After incubation, the slides were washed twice in PBS, then fixed in acetone and air-dried. The slides were put at $-70{ }^{\circ} \mathrm{C}$ for storage.

For IFA testing, the frozen sera were thawed at room temperature and treated at $56{ }^{\circ} \mathrm{C}$ for $30 \mathrm{~min}$ for heat inactivation. The serum samples were serially diluted from $1: 32$ to $1: 512$ by twofold dilutions using PBS (with $10 \%$ skim milk). Thirty microliters of diluted serum was dropped onto each well of slides previously prepared. The slides were incubated at $37^{\circ} \mathrm{C}$ for $40 \mathrm{~min}$ and washed with PBS for $10 \mathrm{~min}$. The secondary antibodies used for serological testings in humans and cats were fluoresceinlabeled goat anti-human immunoglobulin $G$ and goat anti-cat immunoglobulin $G$ (Kirkegaard ${ }^{\circledR}$ Perry Laboratories Inc., Gaithersburg, MD, USA), respectively. They were diluted at 1:400 in PBS, and the mixture was applied to each well. The slides were incubated at $37^{\circ} \mathrm{C}$ for $40 \mathrm{~min}$, washed with PBS for $10 \mathrm{~min}$, and washed again with double distilled water for 10 min prior to reading with a fluorescent microscope (magnification, $\times 400$ ). The intensity of the bacillus-specific fluorescence was scored subjectively from 1 to 4 , and the fluorescence score of $\geq 2$ at dilution of 1:64 was considered to be positive. The seronegative cats were tested by IFA using $B$. henselae $\mathrm{U} 4$ as the antigen.

\subsection{Statistical analysis}

The data were analyzed by $S A S^{\circledR}$ version 6.12 and Microsoft Excel. The chi-square test for homogeneity was used to evaluate the association between disease status (bacteremia or seropositivity) and a categorized risk factor, and $P$ value was calculated using Yates corrected method or two-tailed Fisher's exact test when expected numbers of observations were less than five.

\section{RESULTS}

In the veterinary-associated population, $5(1.7 \%)$ of the 295 persons were seropositive for $B$. henselae. All five seropositive individuals had recalled cat or dog exposures during the last 6 months. No major risk factors that we investigated were associated with seropositivity to $B$. henselae. Univariate analysis by Fisher exact test showed that residence was the only factor associated with seropositivity for $B$. henselae $(P<0.05)$ (Tab. I). However, it was observed that only a few samples were from the eastern area of Taiwan. None of the 107 human blood specimens tested were PCRpositive, but 5 of them were seropositive for Bartonella. Their antibody titers were all at 1:64, which implied past infection.

Bartonella species were successfully isolated from $25(19 \%)$ of the 131 cats tested (Tab. II). These isolates were confirmed to be Bartonella species by PCR/RFLP of the citrate synthase ( $g l t A)$ gene with $T a q \mathrm{I}$ and HhaI digestion. Comparing to the PCR/ RFLP patterns of the reference strains, it was identified that one isolate was $B$. clarridgeiae, and 24 isolates were $B$. henselae (Fig. 1). B. henselae isolates were further genotyped by PCR of the 16S rRNA gene. Because there were two samples with major fungal contamination that could not be analyzed by genotyping of 16S rRNA gene, the 
Table I. Distribution of Bartonella henselae seroprevalences according to different demographic information in 295 veterinary-associated individuals ${ }^{\mathrm{a}}$.

\begin{tabular}{|c|c|c|c|}
\hline Variable & No. of people ${ }^{a}$ & No. of seropositive cases (\%) & $P$-value ${ }^{\mathrm{b}}$ \\
\hline Gender & & & 0.655 \\
\hline Male & 168 & $2(1.2)$ & \\
\hline Female & 127 & $3(2.4)$ & \\
\hline Age (y) & & & 0.715 \\
\hline$<20$ & 10 & $0(0.0)$ & \\
\hline $21-30$ & 94 & $3(3.2)$ & \\
\hline $31-40$ & 49 & $1(2.0)$ & \\
\hline $41-50$ & 28 & $0(0.0)$ & \\
\hline$>50$ & 14 & $1(7.1)$ & \\
\hline Occupation & & & 0.890 \\
\hline Clinician & 108 & $3(2.8)$ & \\
\hline Veterinary technician & 25 & $0(0.0)$ & \\
\hline Public health veterinarian & 24 & $0(0.0)$ & \\
\hline Veterinary student & 128 & $2(1.6)$ & \\
\hline Staff & 10 & $0(0.0)$ & \\
\hline Residential area in Taiwan & & & 0.022 \\
\hline Northern & 158 & $2(1.3)$ & \\
\hline Middle & 115 & $1(0.9)$ & \\
\hline Southern & 19 & $1(5.3)$ & \\
\hline Eastern & 3 & $1(33.3)$ & \\
\hline Clinic work experience (year) & & & 0.081 \\
\hline $0-3$ & 124 & $2(1.6)$ & \\
\hline $4-10$ & 37 & $2(5.4)$ & \\
\hline $11-20$ & 25 & $0(0.0)$ & \\
\hline $21-30$ & 4 & $1(25.0)$ & \\
\hline$>30$ & 4 & $0(0.0)$ & \\
\hline $\begin{array}{l}\text { Scratch or bite incidents in last } 6 \\
\text { months }\end{array}$ & & & 0.162 \\
\hline Yes & 125 & $5(4.0)$ & \\
\hline No & 70 & $0(0.0)$ & \\
\hline Stray animal exposure & & & 1.000 \\
\hline Yes & 88 & $3(3.4)$ & \\
\hline No & 80 & $2(2.5)$ & \\
\hline \multicolumn{4}{|l|}{ Cat/dog at home } \\
\hline Yes & 161 & $5(3.1)$ & 0.589 \\
\hline No & 34 & $0(0.0)$ & \\
\hline
\end{tabular}

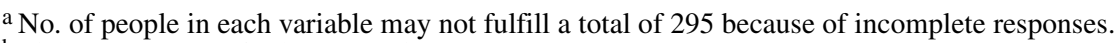

b Fisher's exact test for homogeneity. 


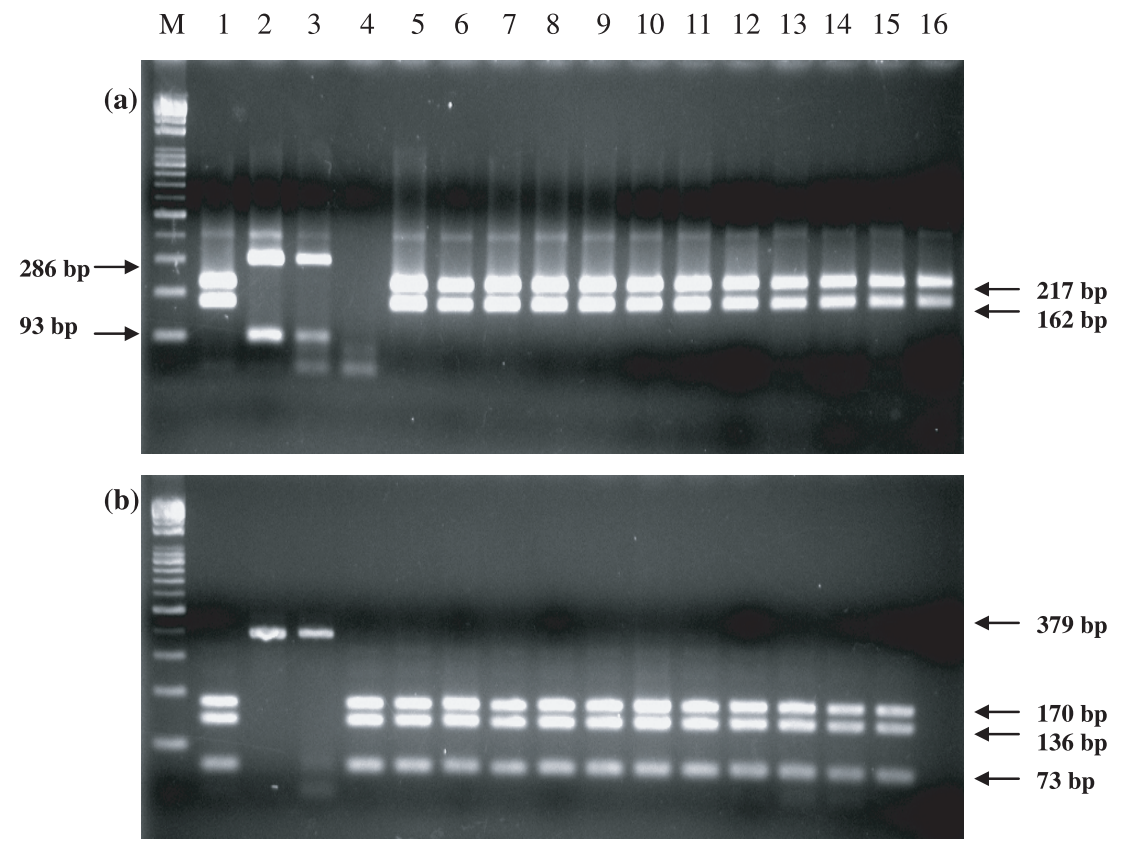

Figure 1. PCR/RFLP of the gltA gene for the cat isolates: (a) with Hha I digestion; (b) with Taq I digestion. M: standard 100-bp molecular ladder; lane 1: B. henselae ATCC 49882; lane 2: B. clarridgeiae ATCC 51734; Negative control: lane 4 of (a) and lane 16 of (b); the other lanes were isolates from cats tested (lane 3 is the cat positive for $B$. clarridgeiae and the other 12 lanes are $B$. henselae positive cats).

Table II. Comparison of Bartonella bacteremic status and seropositivity using B. henselae Houston-1 as the antigen.

\begin{tabular}{lcc}
\hline Bacteremic status & No. of cats & No. of seropositive cats (\%) \\
\hline B. henselae & 24 & $12(50.0)$ \\
Type I only & 7 & $6(85.7)$ \\
Type II only & 3 & $0(0.0)$ \\
Co-infection of type I and type II & 12 & $4(33.3)$ \\
Type unidentifiable (fungal contamination) & 2 & $2(100)$ \\
B. clarridgeiae & $1^{\mathrm{a}}$ & $0(0.0)$ \\
Total & 25 & $12(48.0)$
\end{tabular}

a The cat was co-infected with $B$. henselae type II.

results showed that at least $29.2 \%(7 / 24)$ and $12.5 \%(3 / 24)$ of $B$. henselae bacteremic cats were only infected with $B$. henselae genotypes I or II, respectively. Interestingly, at least $50 \%(12 / 24)$ of $B$. henselaeinfected cats were found to be co-infected 


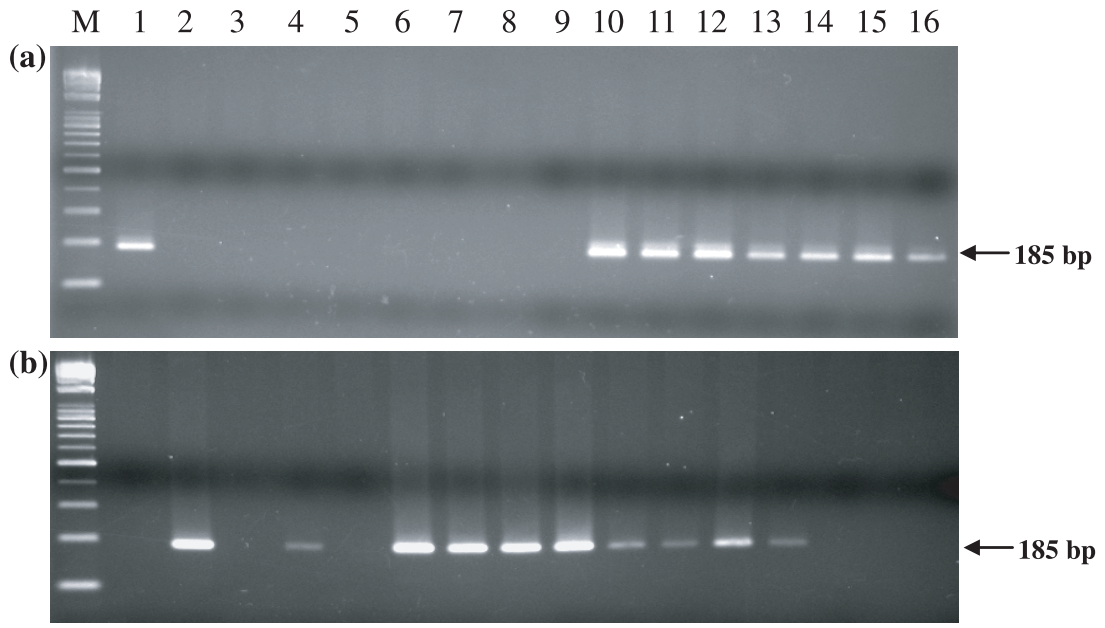

Figure 2. Using 16S rRNA gene for genotyping of B. henselae: (a) cats infected with genotype I; (b) cats infected with genotype II; M: standard 100-bp molecular ladder; lane 1: B. henselae ATCC 49882; lane 2: $B$. henselae U-4 strain; lane 3: negative control; the other lanes were isolates from cats tested.

with genotypes I and II (Fig. 2). It wasidentified that one cat was dually-infected by $B$. clarridgeiae and $B$. henselae type II (Tab. II).

The bacteremia level varied from 30 to $115000 \mathrm{CFU} / \mathrm{mL}$. Fifteen of the 25 bacteremic cats were found to have high level of bacteremia (> $1000 \mathrm{CFU} / \mathrm{mL})$. Most of the bacteremic cats were male $(60.0 \%)$, adult $(88.0 \%)$, with flea infestation $(88.0 \%)$ and impounded cats $(80.0 \%)$ (Tab. III). According to observation by investigators, flea infestation rates varied in cats from origins, ranging from $79.9 \%$ in impounded cats, $46.7 \%$ in pet cats, and $0 \%$ in cats from the cat farm.

Thirty-one $(23.7 \%)$ cats were seropositive for $B$. henselae. The geometric mean titer of the cats tested was 1:128. By univariate analysis (Tab. III), cats with flea infestation were more likely to be bacteremic and seropositive for Bartonella $(P<0.05)$. Cat origin was significantly associated with seropositivity and bacteremia status. Impounded cats had the highest percentages of seropositivity and bacteremia, followed by owners' cats and then cats from cat farm. None of the cats from the cat farm were seropositive nor bacteremic for
Bartonella. Although gender was not a statistically significant factor associated with bacteremia status, male cats were 2.34 times more likely to be bacteremic than female cats. Although there was no significant association (correlation coefficient $=$ $-0.021, P>0.05$ ) between $B$. henselae antibody titer and bacteremia level, it was found that seropositive cats were more likely to be Bartonella bacteremic than seronegative cats $(38.7 \%$ vs. $13.0 \%, P<0.05)$. Furthermore, it was found that more than half (13/ 25 ) of bacteremic cats did not raise antibodies against to $B$. henselae Houston-1, mainly in cats infected with only $B$. henselae type II (3/3) and with $B$. clarridgeiae infection (1/1) and with $B$. henselae types I and II co-infection (8/12) (Tab. II). When these 12 bacteremic but seronegative cats were re-tested by IFA slides coated with type II antigen (B. henselae U-4, University of California, Davis, USA), 9 cats were identified to be seropositive, with ranges of antibody titers from 1:128 to $1: 1024$.

To evaluate the validity of direct PCR detection for determination of bacteremic status, 44 cats were blindly chosen for 
Table III. Univariate analysis of the characteristics of cats associated with Bartonella bacteremia and seropositivity.

\begin{tabular}{|c|c|c|c|c|c|}
\hline \multirow{2}{*}{$\begin{array}{l}\text { Variable } \\
\text { Gender }\end{array}$} & \multirow[t]{2}{*}{ No. of cats } & \multicolumn{2}{|c|}{ No. of seropositive cats (\%) } & \multicolumn{2}{|c|}{ No. of cats with bacteremia (\%) } \\
\hline & & & & & \\
\hline Male & 49 & 11 & $(22.4)$ & 15 & $(30.6)$ \\
\hline Castrated male & 10 & 2 & $(20)$ & 0 & $(0)$ \\
\hline Female & 61 & 17 & $(27.9)$ & 8 & $(13.1)$ \\
\hline Unknown & 11 & 1 & $(9.1)$ & 2 & $(18.1)$ \\
\hline \multicolumn{6}{|l|}{ Age } \\
\hline Adult & 114 & 27 & $(23.7)$ & 22 & $(19.3)$ \\
\hline Juvenile & 17 & 4 & $(23.5)$ & 3 & $(17.6)$ \\
\hline \multicolumn{6}{|l|}{ Flea infestation } \\
\hline Yes & 65 & 23 & $(35.4)^{\mathrm{a}}$ & 22 & $(33.8)^{\mathrm{a}}$ \\
\hline No & 66 & 8 & $(12.1)$ & 3 & $(9.1)$ \\
\hline \multicolumn{6}{|l|}{ Holding condition } \\
\hline Owner's pet & 30 & 8 & $(26.7)$ & 5 & $(16.7)$ \\
\hline Cat farm & 37 & 0 & $(0)$ & 0 & $(0)$ \\
\hline Impounded cats & 64 & 23 & (40) & 20 & $(31.3)$ \\
\hline Total & 131 & 31 & $(23.7)$ & 25 & (19.1) \\
\hline
\end{tabular}

${ }^{a} P<0.05$ by Fisher's exact test for homogeneity.

comparison. The sensitivity and specificity of direct PCR test of the 16S-23S rRNA intergenic region were $60 \%(3 / 5)$ and $67 \%$ (26/39), respectively. The PCR test was with low positive predictive value of $19 \%$ (3/16) and high negative predictive value of 93\% (26/28). Further using the combination of IFA test and direct PCR test to determine bacteremic status, it was found that $96 \%$ $(25 / 26)$ of the cats with negative results by both IFA and direct PCR test were non-bacteremic (Tab. IV).

\section{DISCUSSION}

This is the first epidemiologic study of Bartonella infection in veterinary professionals and cats in Taiwan, since the first human CSD case reported in 1998 [22]. The seroprevalence of $B$. henselae was $1.7 \%$ in veterinary-associated individuals. This prevalence was lower than in previous reports from Japan, which were $15 \%$ in veterinary professionals [20] and $10.9 \%$ in veterinary school students [17]. It was also lower than the $7.1 \%$ in the veterinary population that attended the veterinary Conference in Ohio, USA [30]. Because of the low seroprevalence of $B$. henselae in humans in our study, no significant risk factors were identified to be associated with the infection. Nevertheless, through clinical interviews, all of the five seropositive individuals had a history of animal bite or scratch incidents during the previous 6 months before this survey. Therefore, knowing how to handle animals properly seems to be an important way to reduce the risk of getting CSD infection in Taiwan. 
Table IV. Evaluation of serodiagnosis and PCR method to determine cats with bacteremia.

\begin{tabular}{lcc}
\hline & No. of cats with bacteremia & No. of cats without bacteremia \\
\hline Sero-negative and PCR-negative & 1 & 25 \\
Sero-negative but PCR-positive & 2 & 12 \\
Sero-positive but PCR-negative & 1 & 1 \\
Sero-positive and PCR-positive & 1 & 1 \\
\hline
\end{tabular}

The overall prevalences of seropositivity and bacteremia in cats in Taiwan were $23.7 \%$ and $19.1 \%$, respectively. Our data further indicated that Bartonella seropositivity ranged from $0 \%$ to $16.7 \%$ in pet cats and $31.3 \%$ in impounded cats. Comparing to the results in other Asian countries, the prevalence of Bartonella bacteremia in cats in Taiwan was between that in Japan (7.2$9.1 \%)[25,26]$, and in the Philippines $(61 \%)$ [8]. The study subjects in Japan were mainly pet cats; however, only stray cats were investigated in Philippines [8, 25, 26]. Prevalence of Bartonella infection in cats has been shown to be associated with climatic factors in the USA [15] and Japan [28]. That is, high seroprevalence of the infection in cats correlates with warm and humid climates. As Bartonella infections are mainly transmitted by arthropods, it was hypothesized that climatic factors may affect the distribution of arthropod vectors, including fleas. Our data further suggested that the prevalence of Bartonella infection in Asian cats was associated with countries with different latitudes, from the lowest prevalence in the temperate country (e.g. Japan), the moderate in the sub-tropical country (e.g. Taiwan) and the highest in the tropical country (e.g. Philippines).

Similar to the previous reports from other countries [3, 6, 8], cats with Bartonella bacteremia was strongly associated with flea infestation in our study. In Japan, the prevalence of $B$. henselae in fleainfested cats was significantly higher than that of flea-free individuals [28]. Owing to the humid and warm climate in Taiwan, the flea infestation rates were $79.9 \%$ and $46.7 \%$ in the impounded cats and in the owners' cats in our study, respectively. Among cats from a breeding farm with strict ectoparasite control, none of them were seropositive or bacteremic for Bartonella. The results highlight the importance of flea control in cats to prevent the disease transmission in Taiwan.

Among the 25 bacteremic cats, ten cats were identified to be only infected with B. henselae type I ( 7 cats) or type II (3 cats). However, 12 cats were co-infected with $B$. henselae type I and type II. This is the highest prevalence $(9.2 \%, 12 / 131)$ of coinfection with $B$. henselae type I and type II in cat population that has ever been reported worldwide [4, 13, 27]. In most Asian countries, $B$. henselae isolates from cats belong predominantly to type I, even if the number of cats tested is rather small [5, 26, 27]. Similarly, we identified a higher proportion of Bartonella-bacteremic cats with $B$. henselae type I infection than type II infection.

Yamamoto et al. [35], reported that cats primarily infected with $B$. henselae type I and challenged with $B$. henselae type II showed cross-protection from bacteremia, whereas no cross-protection was previously shown for cats primarily infected with $B$. henselae type II and challenged with $B$. henselae type I [34]. Therefore, it would be reasonable to hypothesize that antibodies against the antigens of $B$. henselae type II might not reacted with the antigens of $B$. henselae type I. Previous reports [11,21] have also shown that cats with $B$. henselae type II or B. clarridgeiae bacteremia could 
be seronegative by IFA when using $B$. henselae Houston- 1 as the antigen. The same results were also identified in our study. Therefore, using B. henselae Houston-1 only as the antigen for sero-diagnosis would underestimate the number of seropositive cats with $B$. henselae type II infection.

A valid test for CSD diagnosis in cats is important for prevention of the disease transmission. Our results indicated that significant association between seropositivity and bacteremic status, while IFA test was with low positive predictive value $(42 \%)$ and moderate negative predictive value $(86 \%)$. Nowadays, PCR machines are available almost in every diagnostic laboratory. Molecular identification of Bartonella DNA using whole blood samples may offer quick reference data. We found direct PCR test of $16 \mathrm{~S}-23 \mathrm{~S}$ intergenic region offers $93 \%$ negative predictive value for determining Bartonella non-bacteremic cats. If the cat was both PCR and IFA negative, the probability of being a non-bacteremic cat could be even higher (with a negative predictive value of $96 \%$ ). Clinically, it seems to be a feasible way to determine Bartonella-free cats from unknown origins.

In conclusion, the study implied the importance of stray cat control in Taiwan for CSD prevention, on the basis of high prevalence of Bartonella bacteremia in this population. Although the seroprevalence of CSD was not high in the veterinary populations that we investigated, people still need to be aware of acquiring the infection through accidental transmission from stray cats living close to human environments.

\section{ACKNOWLEDGEMENTS}

This study was supported in part by grants DOH92-DC-1074 and DOH91-DC-1068 (to Dr Ming Jen Pan) from the Center for Disease Control, Department of Health, Taiwan, ROC, and NSC91-2320-B-039-019 (to Dr Chao-chin Chang) from the National Science Council, Taiwan, ROC.

\section{REFERENCES}

[1] Anderson B., Kelly C., Threlkel R., Edwards K., Detection of Rochalimaea henselae in cat-Scratch disease skin test antigens, J. Infect. Dis. 168 (1993) 1034-1036.

[2] Bergmans A.M.C., Schellekens J.F.P., van Embden J.D.A., Schouls L.M., Predominance of two Bartonella henselae variants among cat scratch disease patients in the Netherlands, J. Clin. Microbiol. 34 (1996) 254-260.

[3] Bergmans A.M., de Jong C.M., van Amerongen G., Schot C.S., Schouls L.M., Bergmans A.M., Schellekens J.F., van Embden J.D., Schouls L.M., Prevalence of Bartonella species in domestic cats in the Netherlands, J. Clin. Microbiol. 35 (1997) 2256-2261.

[4] Birtles R.J., Laycock G., Kenny M.J., Shaw S.E., Day M.J., Prevalence of Bartonella species causing bacteremia in domesticated and companion animals in the United Kingdom, Vet. Rec. 151 (2002) 225-229.

[5] Boulouis H.J., Chang C.C., Henn J.B., Kasten R.W., Chomel B.B., Factors associated with the rapid emergence of zoonotic Bartonella infections, Vet. Res. 36 (2005) 383-410.

[6] Chomel B.B., Abbott R.C., Kasten R.W., Floyd-Hawkins K.A., Kass P.H., Glaser C.A., Pedersen N.C., Koehler J.E., Bartonella henselae prevalence in domestic cats in California: risk factors and association between bacteremia and antibody titers, J. Clin. Microbiol. 33 (1995) 2445-2450.

[7] Chomel B.B., Kasten R.W., Floyd-Hawkins K., Chi B., Yamamoto K., Roberts-Wilson J., Gurfield A.N., Abbott R.C., Pedersen N.C., Koehler J.E., Experimental transmission of Bartonella henselae by the cat flea, J. Clin. Microbiol. 34 (1996) 1952-1956.

[8] Chomel B.B., Carlos E.T., Kasten R.W., Yamamoto K., Chang C.C., Carlos R.S., Abenes M.V., Pajares C.M., Bartonella henselae and Bartonella clarridgeiae infection in domestic cats from the Philippines, Am. J. Trop. Med. Hyg. 60 (1999) 593-597.

[9] Demers D.M., Bass J.W., Vincent J.M., Person D.A., Noyes D.K., Staege C.M., Samlaska C.P., Lockwood N.H., Regnery R.L., Anderson B.E., Cat-scratch disease in Hawaii: etiology and seroepidemiology, J. Pediatr. 127 (1995) 23-26.

[10] Dolan M.J., Wong M.T., Regnery R.L., Jorgensen J.H., Garcia M., Peters J., Drehner D., Syndrome of Rochalimaea henselae 
adenitis suggesting cat scratch disease, Ann. Intern. Med. 118 (1993) 331-336.

[11] Drancourt M., Birtles R., Chaumentin G., Vandenesch F., Etienne J., Raoult D., New serotype of Bartonella henselae in endocarditis and cat-scratch disease, Lancet 347 (1996) 441-443.

[12] Foil L., Andress E., Freeland R.L., Roy A.F., Rutledge R., Triche P.C., O'Reilly K.L., Experimental infection of domestic cats with Bartonella henselae by inoculation of Ctenocephalides felis (Siphonaptera: Pulicidae) feces, J. Med. Entomol. 35 (1998) 625-628.

[13] Gurfield A.N., Boulouis H.J., Chomel B.B., Heller R., Kasten R.W., Yamamoto K., Piemont Y., Coinfection with Bartonella clarridgeiae and Bartonella henselae and with different Bartonella henselae strains in domestic cats, J. Clin. Microbiol. 35 (1997) 2120-2123.

[14] Higgins J.A., Radulovic S., Jaworski D.C., Azad A.F., Acquisition of the cat scratch disease agent Bartonella henselae by cat fleas (Siphonaptera: Pulicidae), J. Med. Entomol. 33 (1996) 490-495

[15] Jameson P., Greene C., Regnery R., Dryden M., Marks A., Brown J., Cooper J., Glaus B., Greene R., Prevalence of Bartonella henselae antibodies in pet cats throughout regions of North America, J. Infect. Dis. 172 (1995) 1145-1149.

[16] Jensen W.A., Fall M.Z., Rooney J., Kordick D.L., Breitschwerdt E.B., Rapid identification and differentiation of Bartonella species using a single-step PCR assay, J. Clin. Microbiol. 38 (2000) 1717-1722.

[17] Kikuchi E., Maruyama S., Sakai T., Tanaka S., Yamaguchi F., Hagiwara T., Katsube Y., Mikami T., Serological investigation of Bartonella henselae infections in clinical catscratch disease-suspected patients, patients with cardiovascular disease, and healthy veterinary students in Japan, Microbiol. Immunol. 46 (2002) 313-316.

[18] Koehler J.E., Glaser C.A., Tappero J.W., Rochalimaea henselae infection - a new zoonosis with the domestic cat as reservoir, J. Am. Med. Assoc. 271 (1994) 531-535.

[19] Kordick D.L., Hilyard E.J., Hadfield T.L., Wilson K.H., Steigerwalt A.G., Brenner D.J., Breitschwerdt E.B., Bartonella clarridgeiae, a newly recognized zoonotic pathogen causing inoculation papules, fever, and lymphadenopathy (cat scratch disease), J. Clin. Microbiol. 35 (1997) 1813-1818.

[20] Kumasaka K., Arashima Y., Yanai M., Hosokawa N., Kawano K., Survey of veteri- nary professionals for antibodies to Bartonella henselae in Japan, Rinsho Byori 49 (2001) 906-910.

[21] La Scola B., Davoust B., Boni M., Raoult D. Lack of correlation between Bartonella DNA detection within fleas, serological results, and results of blood culture in a Bartonellainfected stray cat population, Clin. Microbiol. Infect. 8 (2002) 345-351.

[22] Lee S.C., Fung C.P., Lee N., Shieh W.B., Cat-scratch disease caused by Bartonella henselae: the first case report in Taiwan, $\mathrm{J}$. Formos. Med. Assoc. 97 (1998) 569-572.

[23] Margileth A.M., Baehren D.F., Chest-wall abscess due to cat-scratch disease (CSD) in an adult with antibodies to Bartonella clarridgeiae: case report and review of the thoracopulmonary manifestations of CSD, Clin. Infect. Dis. 27 (1998) 353-357.

[24] Marston E.L., Finkel B., Regnery R.L., Winoto I.L., Graham R.R., Wignal S., Simanjuntak G., Olson J.G., Prevalence of Bartonella henselae and Bartonella clarridgeiae in an urban Indonesian cat population, Clin. Diagn. Lab. Immunol. 6 (1999) 41-44.

[25] Maruyama S., Nogami S., Inoue I., Namba S., Asanome K., Katsube Y., Isolation of Bartonella henselae from domestic cats in Japan, J. Vet. Med. Sci. 58 (1996) 81-83.

[26] Maruyama S., Nakamura Y., Kabeya H., Tanaka S., Sakai T., Katsube Y., Prevalence of Bartonella henselae, Bartonella clarridgeiae, and the $16 \mathrm{~S}$ rRNA gene types of Bartonella henselae among pet cats in Japan, J. Vet. Med. Sci. 62 (2000) 273-279.

[27] Maruyama S., Sakai T., Morita Y., Tanaka S., Kabeya H., Boonmar S., et al., Prevalence of Bartonella species and 16s rRNA gene types of Bartonella henselae from domestic cats in Thailand, Am. J. Trop. Med. Hyg. 65 (2001) 783-787.

[28] Maruyama S., Kabeya H., Nakao R., Tanaka S., Sakai T., Katsube Y., Mikami T., Seroprevalence of Bartonella henselae, Toxoplasma gondii, FIV and FeLV infections in domestic cats in Japan, Microbiol. Immunol. 47 (2003) 147-153.

[29] Nasirudeen A.M.A., Thong M.L., Prevalence of Bartonella henselae immunoglobulin $\mathrm{G}$ antibodies in Singaporean cats, Pediatr. Infect. Dis. J. 18 (1999) 276-278.

[30] Noah D.L., Kramer C.M., Verbsky M.P., Rooney J.A., Smith K.A., Childs J.E., Survey of veterinary professionals and other veterinary conference attendees for antibodies to 
Bartonella henselae and B. quintana, J. Am. Vet. Med. Assoc. 210 (1997) 342-344.

[31] Norman A.F., Regnery R., Jameson P. Greene C., Krause D.C., Differentiation of Bartonella-like isolates at the species level by PCR-restriction fragment length polymorphism in the citrate synthase gene, J. Clin. Microbiol. 33 (1995) 1797-1803.

[32] Regnery R.L., Olson J.G., Perkins B.A., Bibb W., Serological response to "Rochalimaea henselae" antigen in suspected cat-scratch disease, Lancet 339 (1992) 1443-1445.

[33] Szelc-Kelly C.M., Goral S., Perez-Perez G.I., Perkins B.A., Regnery R.L., Edwards K.M., Serologic responses to Bartonella and Afipia antigens in patients with cat scratch disease, Pediatrics 96 (1995) 1137-1142.

[34] Yamamoto K., Chomel B.B., Kasten R.W., Chang C.C., Tseggai T., Decker P.R.,
Mackowiak M., Floyd-Hawkins K.A., Pedersen N.C., Homologous protection but lack of heterologous protection by various species and types of Bartonella in specific pathogen free cats, Vet. Immunol. Immunopathol. 65 (1998) 191-204.

[35] Yamamoto K., Chomel B.B., Kasten R.W., Hew C.M., Weber D.K., Lee W.I., Koehler J.E., Pedersen N.C., Infection and re-infection of domestic cats with various Bartonella species and types: $B$. henselae type I is protective against heterologous challenge with B. henselae type II, Vet. Microbiol. 92 (2003) 73-86.

[36] Ueno H., Muramatsu Y., Chomel B.B., Hohdatsu T., Koyama H., Morita C., Seroepidemiologic survey of Bartonella (Rochalimaea) henselae in domestic cats in Japan, Microbiol. Immunol. 39 (1995) 339-341. 